\title{
An Elaborated Model of Student Support to Allow for Gender Considerations in Asian Distance Education
}
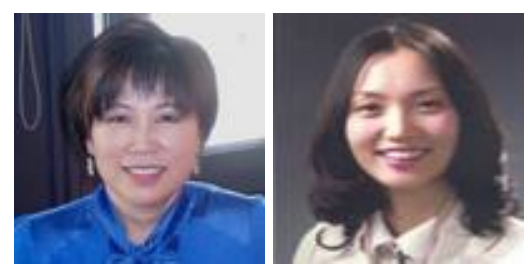

Insung Jung ${ }^{1}$ and Seongyoun Hong ${ }^{2}$

${ }^{1}$ International Christian University, Japan, ${ }^{2}$ Ajou University, Korea

\section{Abstract}

Research indicates that distance education (DE) students regard learner support systems as the key element in quality provision. This study sought to identify the key concerns of Asian DE students regarding support provision in different types of DE and dual-mode providers and formulate a student support model which took account of gender issues. An online survey was conducted with 1,113 distance learners in Japan, Korea, Hong Kong SAR China, Malaysia, India, Pakistan, Philippines, Singapore, and Thailand which required them to respond to open-ended questions regarding their main concerns over the quality of distance education. Their responses were analyzed with Nvivo 2.0 based on the framework of the Atkins (2008) ARCS model of distance learner support. It was found that in assessing the quality of DE the students valued 13 types of student support across five domains: affective, reflective, cognitive, systemic, and gender-considerate. It was also confirmed that there were gender differences in the students' perceptions of the need for student support. Building on these findings, an elaborated model for student support for Asian distance learners was developed from a systems perspective, and from this, a list of supporting strategies was proposed.

Keywords: Asian distance education; distance learner support; quality assurance; student support 


\section{Introduction}

Distance education (DE) students often judge the quality of DE courses by the academic and non-academic services provided by their institutions. The academic aspects include course design/ development, learner support, flexibility and interaction, and the nonacademic aspects include the costs and convenience of study and employability after graduation (Latchem \& J ung, 2009). Rumble (2000), Frydenberg (2002), J ung (2011), and Tang and Husin (2011) reveal the extent to which student support affects persistence and success in distance learners, stressing that this is one of the most critical factors in assuring quality in DE provision. Tait and Mills (2013) argue that given recent changes in DE such as inter-institutional and international competition, commercialism, the learner as consumer, and the larger enrollments and greater diversity in the learners' prior learning, abilities, cultural backgrounds and needs, the nature and quality of student support is of even greater significance.

While conventional universities may regard student support as ancillary because they assume that the on-campus students have regular face-to-face contact with their tutors and peers, when it comes to DE institutions, as Thorpe (2002, p. 106) points out, 'all aspects of an institution's provision . . . should be supportive in the sense of fostering high quality learning. A survey conducted with Asian distance learners by J ung (2012) supports this view by revealing that student support is the students' core concern in assessing quality in DE and that they expect clear and adequate study guidance; appropriate DE study skills training; continuous media/technology support; needsbased social, administrative, financial, and psychological support; flexibility and fairness in learning provision and evaluation; and frequent feedback.

Many studies have been carried out into various kinds of student support and their implications in a range of DE contexts (e.g., by Ludwig-Hardman \& Dunlap, 2003; Mandernach, 2009; Sewart, 1993), but few studies have offered a theoretical model to explain the key dimensions of student support from the learners' perspective. Mactague (2004) presents a model of academic learner support services for DE in higher education in which she outlines the specific methods of student support, assessment, remediation, tutoring, orientation, community building, mentoring, counseling, and professional development needed to help the students improve their research, writing, and time management skills, integrate practicum and coursework, and complete their dissertations on time. This model also specifies how to relate these support methods to students' academic needs. While Mactague's model focuses mainly on cognitive aspects of student support, Tait (2000) suggests that student support in DE should not only be cognitive (supporting and facilitating learning), but affective (supporting emotional/psychological aspects) and systemic (supporting students with rules and instructional systems) and again appropriate to the needs of diverse students. Atkins (2008, 2009) expands Tait's framework by adding reflective support (developing the capacity to reflect on action so as to engage in continuous learning). Atkins' model concerns student support in four domains (Affective, Reflective, Cognitive, and 
Systemic) and so is known as the ARCS model. It provides the basis for the UK Open University student support system (Stevens \& Kelly, 2012).

While four domains suggested in the Atkins' multidimensional ARCS model can be applied beyond the OU contexts, there might be other domains that are uniquely important in contexts where DE is regarded as a 'second rate' mode of education, where the students may be more accustomed to teacher-dependent schooling, where they may be more socially and economically disadvantaged, and where there is a more serious gender divide, as in Asia.

Regarding gender divide in the Asian DE contexts, Green and Trevor-Deutsch (2002) observe that female students in Asian DE tend to face more serious barriers than male students when the course content is not directly relevant to their livelihood; when access to the content is too costly; and when they do not feel able to use the technology competently. Taplin (2000) also reveals that personal or family problems and difficulties with getting course materials in time to complete assignments or examinations were the major problems for female students in Asian DE who were considering dropping out of their DE programs. Maybe that is why the Asian female students tend to receive more support socially, psychologically, and logistically than they do academically as found in Jung and Fukuda (2011).

While previous studies including those mentioned above have identified gender differences in the Asian DE contexts, few studies discuss gender mainstreaming that is a globally accepted strategy in tertiary education for promoting gender equality and needs to be reflected in the planning, implementation, and monitoring of all programs (Vimala, 2010). Jung (2007) has documented good practices in DE to ensure that learners, especially women, receive institutional support in order to successfully complete their studies. This involves a shift from a provider-centered to a learnercentered approach of student servicing and tutoring and close monitoring. The present study therefore aimed to elaborate the ARCS model by drawing upon Asian DE students' perceptions of quality support, identify any further dimensions that might be needed in regard to gender, and explore some gender mainstreaming strategies to meet different support needs of female and male DE students in Asia.

\section{Theoretical Framework}

Atkins's (2008) ARCS model was seen as the most appropriate model to take as a starting point because it is well tested, takes the distance learners' perspectives into account and includes both the academic and non-academic aspects of the support required for DE students, while other models such as Mactague's tend to reflect the DE provider's view, focus largely on the academic aspects, and ignore the learners' support needs for affective and reflective domains. The ARCS model categorizes student support services into four domains: affective, reflective, cognitive, and systemic. 
- The affective domain concerns such questions as How do I feel about studying? Am I confident and finding pleasure in it? It includes a variety of services that aim to help distance learners promote personal development at both self and social levels. Suggested services include strategies to help students develop identity, values and beliefs, interests, and potential as students of a particular subject, boost confidence and independence, sustain motivation and celebrate success, and develop selfmanagement skills.

- The reflective domain addresses such questions as Why am I doing this study? What are my motivations? It includes both assistive and developmental supports. Assistive supports are the provision of information, advice, and guidance regarding subject matter, finance and fees, disability and additional requirements, and admission and registration, whereas developmental supports focus on the provision of information, advice, and guidance to help the distance learners clarify their objectives and feelings about their studies and strengthen their motivation and ability to manage their emotions.

- The cognitive domain addresses such questions as What am I learning and developing? Does it make sense to me? It includes the means of helping distance learners gain the kinds of knowledge they need to satisfy their learning needs and apply these to real-life situations. Examples contain supports for formative assessment, feedback on assessment and on other activities, subject knowledge acquisition, navigation of learning media, and preparation for assessment including exams.

- The systemic domain covers such questions as Who and what is helping me with studying? Do these support me? It includes assistance in such areas as registration, progress through learning, assessment and accreditation, library access, technical support, and all affective, reflective, and cognitive support needed for successful learning.

The current study sought to answer the following questions:

1) Is the general framework of the ARCS model applicable to Asian DE contexts?

2) Would an elaborated model be needed in regard to Asian DE students' support needs? If so, what other domains and types of support should be added to the ARCS model?

3) Are there gender differences in Asian DE students' perceptions and how can these differences be reflected in the student support system? 


\section{Method}

\section{Participants}

The participants in this study were 1,113 distance learners enrolled in DE institutions or programs in Japan, Korea, Hong Kong SAR China, Malaysia, India, Pakistan, Philippines, Singapore, and Thailand. They were asked to respond to closed items for another study (Jung, 2012) and provide answers to three open questions for the purposes of this study which was undertaken between J une and October 2010.

Seventy percent (775) of those contacted, $67 \%$ of whom were male, completed the open questions as requested. Forty-nine percent were aged $21-30$ and $22 \%$ were aged 31-40. Around $46 \%$ of the students were enrolled in DE universities, 31\% were engaged in DE programs offered by conventional universities, and the remaining $23 \%$ were taking DE courses provided by overseas DE universities, for-profit providers, their own companies, or non-government organizations. Around $46 \%$ were studying mainly through print/correspondence and almost $20 \%$ were studying entirely online. The remainder was studying by mixed means.

\section{Instrument}

The online survey included three open questions. The first question asked the main concerns of male students regarding the quality of $\mathrm{DE}$, and the second one asked the main concerns of female students in relation to the quality of DE. The third question asked students to make additional comments or suggestions regarding the quality of service of DE considering their own gender-related needs.

\section{Procedure}

Following a general ethics code for research, the survey proposal was reviewed and approved by the Academic Affairs' Office at the first author's university. An invitation email was sent out to lecturers teaching DE courses at the different types of Asian institution including state-funded mega universities, small and large private institutions, dual-mode universities, for-profit e-learning companies, community centers, and NGOs. These faculty members distributed the survey link to their students in various major areas to respond online.

\section{Data Analysis}

The 1,540 responses to the three open questions from the 775 respondents were exported to Nvivo 2.0 for the purposes of classifying and organizing the nonnumerical data, examining relationships in the data, and combining analysis with modeling. Responses without particular meaning were eliminated, and 1,317 responses were then used for the initial coding. The code classification process was cyclic, 
following four stages: meaning-making, reduction, elaboration, and modeling. This process was repeated several times until there was total concurrence between the two authors.

At the meaning-making stage, the 1,317 responses were analyzed to identify significant chunks for coding. Where responses included more than one concern, each concern was recorded as a significant chunk. In total, 1,872 significant chunks were identified and categorized into 84 codes. Code names were created to highlight the representative meaning of significant chunks.

At the reduction stage, these chunks and code names were reviewed by the authors to see if each chunk was appropriately assigned to a code representing its most important meaning, and whether some chunks could be combined because they represented similar meanings. As a result of two rounds of this review process, 84 codes were decreased to 71 codes, and again to 47 codes.

At the elaboration stage, all 47 codes were once again reviewed and the code names were refined several times. Finally, 37 codes remained, each having a distinctive name highlighting the meaning of the included chunks.

At the modeling stage, these 37 codes were categorized using the four domains in the ARCS model. During this process, some codes were combined, a few code names were once more refined, and a new domain was created to include those codes which did not belong to the ARCS' four domains. Eventually 1,785 chunks (from the initial 1,872) and 33 codes (from the initial 84) were included in the final modeling process, and classified into five domains: affective, reflective, cognitive, systemic, and gender-considerate. A code was re-titled as 'focus of support' and similar sub-elements were grouped as a 'type of support'. In total, 13 types of support were created and 33 focuses of support, as presented in Table 1. Responses by male and female students were compared across the five domains and sub-categories.

\section{Results}

\section{Coding and Categorization}

The general framework of the ARCS model was found to be applicable to Asian DE contexts but the study confirmed the need to consider the gender dimensions. The open ended responses were therefore classified into five domains (affective, reflective, cognitive, systemic, and gender-considerate support domains) as shown in Table 1. During the four-stage analysis process, it was found that the affective domain required three types of support (social, practical, and emotional support); the reflective domain required two types of support (developmental and assistive guidance); the cognitive 
domain required three types of support (strategic learning, content, and tutorial and assessment support ); the systemic domain required two types of support (policy and customized support); and the gender-considerate domain required three types of support (life skills development, policy and learning environment, and confidence building). Examples in Table 1 show indicative types of responses from the Asian DE learners in each of the 33 focuses of support.

Table 1

Coding and Categorization of Support Services Perceived Important for Quality DE by Asian Distance Learners

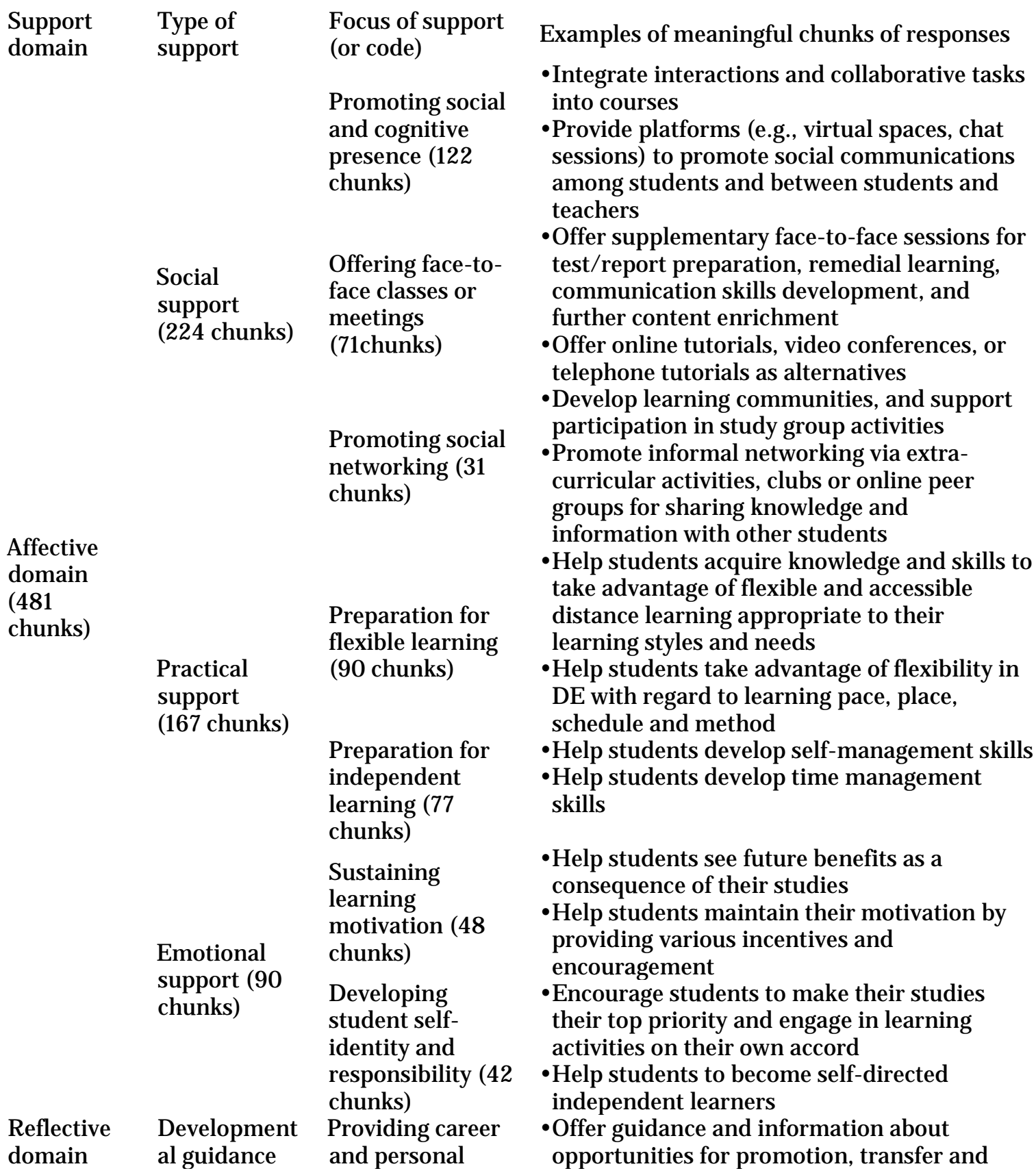


(199

chunks)
(119 chunks)

Assistive guidance (80 chunks)

Strategic learning support (188 chunks)

Cognitive domain (504 chunks) development opportunities (88 chunks) Preparing essential literacy (31 chunks)

Offering guidance and information on academic matters (49 chunks)

Obtaining support from family and workplace (16 chunks)

Offering financial support (15 chunks)

Developing effective distance learning strategies (110 chunks)

Facilitating knowledge acquisition (46 chunks)

Offering opportunities for further studies (32 chunks)

Providing relevant learning resources (67 chunks)

Content support (165 chunks)
Offering practical and applicable content (54 chunks) Offering up-todate content (44 chunks) new employment as a consequence of successful completion of the study

- Offer job-hunting or internship opportunities

- Offer training in basic computer skills and communication skills

- Assist students in effectively accessing using various resources for their studies

- Offer guidance and information on rules and processes of admission, transfer and graduation

- Provide detailed information on study methods, assignments and tests prior to registration and periodically via online, mobile phone or social media systems

- Promote the various benefits of DE to gain emotional support from students' family and workmates

- Organize appropriate learning schedules to suit students' family and work obligations

- Offer direct or indirect financial support to students in need

- Provide financial support or rental assistance for laptops and other technologies required for study

- Integrate DE strategies into courses and materials to acquaint students with effective distance learning strategies appropriate to their learning styles

- Help students improve their learning methods via periodic meetings, discussions, or technology-mediated methods

- Integrate appropriate design strategies to help students grasp the key concepts and ideas in courses and materials

- Provide teaching and learning materials which include concrete examples and explanations to help students master the content

- Offer further studies to advanced students (e.g., in the forms of additional or more demanding assignments, extra readings, classes etc.)

- Provide optional workshops, external activities and hands-on experience to meet the needs and interests of advanced students

- Provide detailed and comprehensive reading materials, lecture notes, video clips and related learning materials

- Offer multimedia resources including videos and animations to promote engaging and interactive learning

- Integrate practical and applicable knowledge and skills in courses and materials

- Offer materials which will be relevant to students after graduation

- Update content and curriculum as often as necessary

-Improve study materials in accord with 
Tutorial and assessment support (151 chunks)

Policy support (209 chunks)

Systemic domain (295 chunks)

Genderconsiderate Domain (306 chunks

Customized support (86 chunks)

Life skills development (166 chunks)
Offering timely tutorials (87 chunks)

\section{Offering quick} feedback on assignments and tests (46 chunks) Applying fair assessment criteria (18 chunks) Developing and implementing policies to create a supportive learning environment (119 chunks) Meeting external quality standards (90 chunks)
Implementing a flexible payment system (36 chunks) Locating study centers close to learners (29 chunks)

Integrating learners' opinions in institutional policy (21 chunks) Developing skills to balance life, work and learning (146 chunks) Developing skills to manage the innate nature of gender (20 chunks)
- Hire sufficient well qualified or experienced tutors and instructors for DE lecturing and tutoring

- Secure sufficient number of tutors and instructors who can answer students' queries by face-to-face or online means

- Offer prompt and accurate feedback on assignments, quizzes/tests, portfolios, etc.

- Reply promptly to the students' questions/concerns

- Develop policies to assure fair and equitable admissions and assessments, and prohibit cheating/ plagiarism, etc.

- Provide clear and detailed assessment criteria

- Offer inclusive, user-friendly learning environments which include easily accessible virtual learning systems, digital libraries, and 24-hour services

- Undertake frequent inspections of DE systems and technologies and students, perceptions of these

-Ensure a high reputation for DE institutions by meeting high quality standards for academic accreditation at national and international levels

- Improve public perceptions of DE degree study in comparison with conventional education

- Charge affordable tuition and other fees

-Allow students to pay tuition and other fees by installment

-Ensure easy access to study centers, libraries, etc.

- Organize science labs, seminar rooms, computer labs, etc. close to students' locations

- Conduct student surveys regularly and consult student representative(s)

- Use the results of students' opinions in improving policies and programs - Offer students training in balancing lifestyles, study and domestic and workplace demands

- Pay special attention to female students and their demands of work and family

- Help students appreciate gender differences in learning

- Overcome any innate gender-specific characteristics which impede learning (e.g., offering encouragement to shy female students who post messages, and assisting male students with low level of concentration to develop attention maintenance skills) 
Policy and learning environment (81 chunks)
Reducing gender discrimination (50 chunks)
-Implement policies and strategies to reduce gender discrimination or stereotyping in admissions, courses, courseware, learning support and assessment

- Provide a supportive learning environment for female students experiencing social and familial prejudices

- Be responsive to gender differences in learning in courses and services(e.g., by offering more structured, interactive or shortterm sessions for male students as they are found to be less likely to engage in online discussions)

- Offer gender-specific academic support (e.g., additional support for female students showing lower levels of technology competencies or mathematical skills)

Establishing a secure learning environment (10 chunks)

- Enforce rules and regulations to ensure safe learning environments that are free from violence (both physical and verbal) and sexual threat, especially for female students

- Reinforce security in study centers Improving overall $\cdot$ Blend distance or online learning modes with

Confidence building ( 59 chunks)

Improving confidence in distance learning (33 chunks)

face-to-face sessions to develop students' confidence in distance learning

- Allow female students to ask questions directly to tutors or instructors before publicly posting messages

- Offer both on-demand and continuous technology selfefficacy (26 chunks) technical training and support

-Adapt an easy-to-use learning management system (LMS) and offer step-by-step guidance in using it

\section{Gender Differences in Student Support}

Analyzing and comparing the concerns of the male and female respondents, several gender differences in students' perceptions became apparent.

1. The affective domain in general was regarded as more important by the male students (182 chunks) than the females (121 chunks), although more males indicated that Offering face-to-face classes or meetings and Feeling ready for independent learning were more important than did the females.

2. The reflective domain was also perceived to be more important by males ( 82 chunks) than females (48 chunks) and, in particular, the economic and developmental aspects such as Offering financial support and Providing career and personal development opportunities.

3. The cognitive domain was similarly perceived as more important by males (135 chunks) than the females (74 chunks), particularly in regard to Offering practical 
and applicable content. Both genders perceived Developing effective distance learning strategies and Offering timely tutorials as the most important type of support in this domain.

4. In regard to the systemic domain, Developing policies to create a supportive learning environment was regarded as the most important type of support by males and females alike, while Implementing a flexible payment policy and Integrating learners' opinions in institutional policy were seen as more important by the males.

5. The gender-considerate domain revealed types of support that were regarded as more important by females than males, for example, Develop skills to balance life, work and learning, Reduce gender discrimination, Improve technology selfefficacy and Overall confidence in distance learning. Only the female respondents (9 chunks) expressed concern for Establishing a secure learning environment.

\section{Discussion}

To address the complexities of student support, the design and implementation of student support services needs to be addressed holistically, employing a systems approach which is a process of understanding how elements of a system influence one another within a whole system and in relation to its external environment, and making decisions accordingly (Littlejohn, 1996). Tackling any one of the five domains in the student support model without considering the others or taking the external environment into account will inevitably fail to meet the learners' needs.

A conceptual model of systemic student support for Asian distance learners was therefore proposed as an elaborated, gender-considerate version of the ARCS model. Figure 1 shows the key components of the five domains in this model.

- Affective support helps the distance learners remain motivated and connected during the course of their studies and to become successful independent learners.

- Reflective support helps the distance learners become reflective in regard to academic and non-academic matters.

- Cognitive support promotes effective and efficient learning by providing appropriate content, resources, tutorials, and assessment.

- Systemic support is provided through institutional policies and systems for all students and customized support at the individual level.

- Gender-considerate support addresses the socio-economic, cultural, and educational barriers that can still seriously impede females' participation and success in higher education study. 


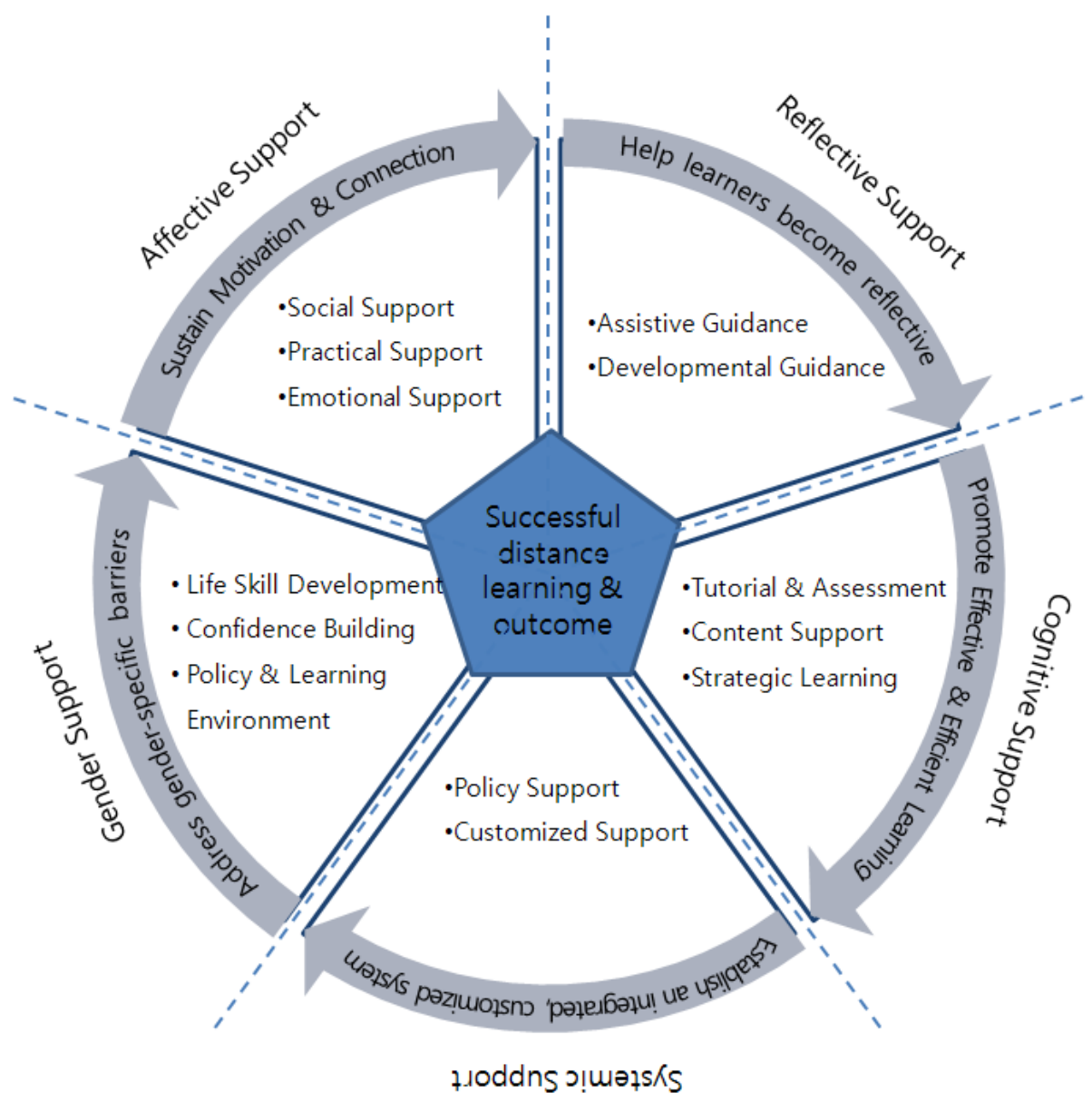

Figure 1. A model of systemic student support for Asian distance learners.

Support strategies that may be particularly useful for Asian distance learners in each of the five domains are suggested based on the survey results and other related studies.

In the affective domain, promoting social and cognitive presence is seen as the most important form of support required. Social presence, the learners' feeling of belonging to a learning community and having instructors and tutors who care for them, can be promoted by providing, for example, virtual spaces, chat sessions, uses of social media for welcoming messages, student profiles, audio/video introductions, sharing instructor's personal stories and opinions, using humor and emoticons and peer-to-peer learning and embedding these in the course design (Aragon, 2003). Cognitive presence, the extent to which learners are able to construct and confirm meaning through sustained reflection and discourse in a critical community of inquiry' (Garrison, Anderson, \& Archer, 2001, p. 9), can be promoted by engaging learners in critical inquiry, integrating interactions and collaborative tasks in DE courses, and scaffolding discussions by posting meaningful questions and leading the learners to find resolution 
and reach consensus, as suggested by Darabi, Arrastia, Nelson, Cornille, and Liang (2011).

In the reflective domain, the most valuable support for Asian distance learners would be guidance for career and personal development. As Abdullah (2004) observes, the majority of Asian distance learners are in low or middle level jobs and have poor academic backgrounds, so if $\mathrm{DE}$ is to help them climb the career ladder, DE institutions must offer clear and positive guidance and information on opportunities for promotion, job transfer, employment, and internships.

In the cognitive domain, the most important support would be helping the students to improve their self-learning strategies. This calls for appropriate orientation programs before the commencement of formal study and on-demand periodic meetings and discussions and/or technology-mediated training and advisory sessions throughout the course of study. These are needed to develop the cognitive skills necessary for the learners to develop the capacity to preview, organize, and review content for the purposes of independent or minimally supervised learning, apply elaboration strategies in order to develop ever deeper understanding of the content and ability to apply this learning in different contexts, and the meta-cognitive skills necessary to plan and regulate their learning progress and learning strategies in accord with their particular learning styles and circumstances (Hong \& J ung, 2011). Time management skills also need to be developed as these are important for distance learners who typically have to cope with multiple responsibilities (Levy, 2007).

In the systemic domain, DE institutions need to make the effort to provide supportive, inclusive, and user-friendly learning environments for all of their learners, regardless of their locations and circumstances. These should include easily accessible, user-friendly virtual learning spaces, communication channels, digital libraries, 24-hour on-call or online services, online payment systems, technical help desks, and social networking opportunities for peer support and sharing learning and experiences (Alias \& Rahman, 2005).

In the gender-considerate domain, caution is needed in regard to gender stereotyping and gender inequality, both for men and women. For example, while both genders may need financial support or flexible payment systems, in certain Asian contexts, this may be more important for males than females because it can be the men who have the prime financial responsibility, not only for their own families but also for their extended families.

However, female participants may need special support because their participation and success can be influenced by a number of factors:

- The nature and quality of the secondary education they received (in some countries, girls' high schools have different curricula from co-educational or boys' schools, do not teach science and mathematics at an advanced level and as a consequence, girls 
cannot enter certain university departments and if they do, may struggle with the content and methods)

- Their economic circumstances

- Their locations and the availability of study and support

- $\quad$ Class, caste, race, and occupation-related identity issues

- Cultural and religious norms governing gender relations

- Early marriage, child-raising, household responsibilities, and pressures to work leading to problems in balancing lifestyle, work and learning, assignment and examination. That is a common cause of dropout as confirmed in a study of Indian female distance learners by Taplin (2000).

- Mindsets and gender stereotyping which encourage women to pursue careers in child development, education, medicine (nursing), and service sector occupations (Vimala,2010).

Support to counter or compensate for these factors can be offered by means of formal and informal face-to-face or online sessions dealing with such matters as time management (Hong \& J ung, 2011) and providing flexible study schedules or classroom attendance requirements (J ung, 2012).

Assisting female distance learners with their confidence with and use of information and communications technology (ICT) and other DE tools and methods is also found to be important in the study. Several studies conducted in Asia report on male students' higher self-efficacy in ICT and DE, for example, Atan, Azli, Rahman, and Idrus (2002) in regard to Malaysian undergraduates, Tekinarslan (2009) in regard to Turkish undergraduates, and Zhang, Li, Duan, and $\mathrm{Wu}$ (2001) in regard to Chinese undergraduate and graduate students. All of these studies indicate need for scaffolding, personal tuition, and technical support, particularly for female distance learners.

Sadly, the last twenty years have seen a significant increase in media reporting on gender-based violence including sexual harassment in educational institutions. It can also be the case that overt and subtle forms of sexual harassment influence the ability of women to pursue higher education (Vimala, 2010). As indicated by several participants of this study, there is therefore need for safe and secure learning environments for female students in countries such as India and Pakistan where incidents of sexual harassment or violence toward females occur in and around study centers. 


\section{Conclusion}

Student support is critical to the success, status, and quality of DE. The present study confirmed the usefulness of the four support dimensions of the ARCS model in Asian DE contexts. But it also identified one gender-related dimension needed and proposed a systemic, conceptual model of student support based upon the views of Asian distance learners. This conceptual model provided the basis for suggested support strategies appropriate to Asian contexts and beyond.

It is acknowledged that this study has its limitations. It did not examine any differences between the conditions of learners in the various Asian countries so the results and recommendations may not apply in every country, economy, or social and learning culture. So caution is needed in interpreting the conceptual model and further studies are required to consider these diversities, the culture-specific gender issues, and need for gender-considerate support. Finally, these data were collected in 2010. Since that time, Asian countries' technological infrastructure has been improved, DE has been more widely accepted by the public, and the DE policies have changed. The impact of these changes also calls for further investigation.

\section{Acknowledgements}

This study was funded by the Openness and Quality in Asian Distance Education Project from the International Development Research Centre (IDRC) of Canada in 2010. 


\section{References}

Abdullah, S. (2004). Students in distance and open learning: The Asian experience. In H. Perraton \& H. Lentell (Eds.), Policy for open and distance learning: World review of distance education and open learning (pp. 66-75). New York: Routledge.

Alias, N. A., \& Rahman, N. S. N. A. (2005). The supportive distance learning environment: A study on the learning support needs of Malaysian online learners. European J ournal of Open and Distance Learning. Retrieved from http://www.eurodl.org/materials/contrib/2005/Alias Rahman.htm

Aragon, S. (2003). Creating social presence in online environments. New Directions for Adult and Continuing Education, 100, 57-68.

Atan, H., Azli, N., Rahman, Z., \& Idrus, R. (2002). Computers in distance education: Gender differences in self perceived computer competencies. J ournal of Educational Media, 27(3), 123-135.

Atkins, P. (2008). Transformation and integration through research and enquiry: A centre for excellence in teaching and learning perspective. In M. Weaver (Ed.), Transformative learning support models in higher education: Educating the whole student (pp. 181-196). London: Facet Publishing.

Atkins, P. (2009). ARCS-an integrating model of learning support for an integrated future? Retrieved from http:// www.open.ac.uk/ opencetl/files/opencetl/ file/ ecms/ web-content/ARCSPoster.pdf

Darabi, A., Arrastia, M. C., Nelson, D. W., Cornille, T., \&Liang, X. (2011). Cognitive presence in asynchronous online learning: A comparison of four discussion strategies. J ournal of Computer Assisted Learning, 27, 216-227.

Frydenberg, J . (2002). Quality standards in eLearning: A matrix of analysis. The International Review of Research in Open and Distance Learning, 3(2). Retrieved from http:/ / www.irrodl.org/ index.php/irrodl/ article/view/ 109/ 189

Garrison, D. R., Anderson, T., \&Archer,W. (2001). Critical thinking, cognitive presence and computer conferencing in distance education. The American J ournal of Distance Education, 15(1), 7- 23.

Green, L., \& Trevor-Deutsch, L. (2002). Women and ICTs for open and distance learning: Some experiences and strategies. Vancouver: Commonwealth of Learning. Retrieved from http:// www.col.org/SiteCollectionDocuments/ women\%20and\%20ICTs.pdf 
Hong, S., \&J ung, I.S. (2011). The distance learner competencies: A three-phased empirical approach. Educational Technology Research and Development, 59(1), 21-42.

J ung, I. (2007). Innovative practices of distance education (including e-learning) in Asia and the Pacific. International J ournal for Educational Media and Technology, $1(1), 48-60$.

J ung, I. (2011). The dimensions of e-learning quality: From the learner's perspective. Educational Technology Research and Development, 59(4), 445-464.

J ung, I. (2012). Asian learners' perception of quality in distance education and gender differences. The International Review of Research in Open and Distance Learning, 13(2), 1-25.

J ung, I.S., \& Fukuda, A. (2011, September 30). Gender differences in Asian learners' perception of the quality in distance education and e-learning: Implications for a gender-considerate support system. Paper presented at the 25th AAOU conference. Penang, Malaysia.

Latchem, C., \&J ung, I. S. (2009). Distance and blended learning in Asia. New York and London: Routledge.

Levy, Y. (2007). Comparing dropouts and persistence in e-learning courses. Computers and Education, 48(2), 185-204.

Littlejohn, S. W. (1996). System theory. In S. Littlejohn, Theories of human communication (pp. 42-63). Belmont, CA: Thomson Learning Global Rights Group.

Ludwig-Hardman, S., \& Dunlap, J . (2003). Learner support services for online students: Scaffolding for success. The International Review of Research in Open and Distance Learning, 4(1). Retrieved from http:// www.irrodl.org/index.php/irrodl/article/view/131/211

Mactague, N. J . (2004). Development of a model of academic learner support services for distance education programs for higher education. In U. Bernath \&A. Szucs (Eds.), Supporting the learner in distance education and e-learning (pp. 348355). Oldenburg, Germany: Bibliotheks- und Informationssystem der Universitaet Oldenburg.

Mandernach, B. (2009). Effect of instructor-personalized multimedia in the online classroom. The International Review of Research in Open and Distance Learning, 10(3). Retrieved from http:// www.irrodl.org/index.php/irrodl/article/view/606/ 1263 
Rumble, G. (2000). Student support in distance education in the 21st Century: Learning from service management. Distance Education, 21(2), 216-235.

Sewart, D. (1993). Student support systems in distance education. Open Learning, 8(3), 3-12.

Stevens, C., \& Kelly, P. (2012). Change and renewal: The role of a change team in improving student support. Open Learning: The Journal of Open, Distance and e-Learning, 27(2), 137-148.

Tait, A. (2000). Planning student support for open and distance learning. Open Learning, 15(3), 287-299.

Tait, A., \& Mills, R. (Eds.). (2013). Rethinking learner support in distance education: Change and continuity in an international context. New York: Routledge.

Tang, S. F., \&Hussin, S. (2011). Quality in higher education: A variety of stakeholder perspectives. International J ournal of Social Science and Humanities, 1(2), 126-131.

Taplin, M. (2000). Problems experienced by female distance education students of IGNOU: Why do some consider dropping out while others decide to stay? Indian J ournal of Open Learning, 9(2), 191-210.

Tekinarslan, E. (2009). Turkish university students' perceptions of the world wide web as a learning tool: An investigation based on gender, socio-economic background, and web experience. The International Review of Research in Open and Distance Learning, 10(2). Retrieved from http:// www.irrodl.org/index.php/irrodl/article/ view/ 598/ 1217

Thorpe, M. (2002). Rethinking learner support: The challenge of collaborative online learning. Open learning, 17(2), 105-119.

Vimala, R. (2010). Gender issues in higher education - Advocacy Brief. Bangkok: UNESCO Bangkok. Retrieved from http:// unesdoc.unesco.org/images/0018/001898/189825e.pdf

Zhang, J., Li, F., Duan, C., \&Wu, G. (2001). Research on self-efficacy of distance learning and its influence to learners' attainments. In C.H. Lee (Ed.), Proceedings of the International Conference on Computers in Education (ICCE)/ SchoolNet 2001 (pp. 1510-1517). Incheon, South Korea: Incheon National University of Education. 


\section{Athabasca University $\mathbf{A}$}

(c) (i) 